\title{
Prescription Drug Costs and the Generic Dispensing Ratio
}

\author{
Joshua N. Liberman, PhD, and M. Christopher Roebuck, MBA
}

\begin{abstract}
BACKGROUND: The generic dispensing ratio (GDR) - the number of generic fills divided by the total number of prescriptions-is a standard performance metric on which pharmacy benefit designs and their managers are routinely evaluated. Higher GDRs are considered important because they consistently produce lower prescription drug costs.

OBJECTIVE: To (a) quantify the relationship between GDR and gross pharmacy expenditures and (b) distinguish pharmacy cost savings realized from brand-to-generic conversion from those due to brand drug utilization decreases.

METHODS: This study was a longitudinal, retrospective analysis of paid pharmacy claims and insurance eligibility information for 548 employers covering nearly 14 million members. Data were from the period January 1 , 2007, through December 31, 2009, aggregated quarterly. In a linear fixed effects model controlling for plan membership demographics and time trends, percentage changes in gross pharmacy expenditures per member per quarter (PMPQ) were associated with changes in GDR. A second model estimated the association of GDR with gross pharmacy cost, holding total drug utilization constant. All claims counts were adjusted to 30 -day equivalents, and expenditures were log-transformed.
\end{abstract}

RESULTS: Mean generic claims PMPQ increased by $18.4 \%$ during the study period, from 2.01 in 2007 Q1 to 2.38 in 2009 Q4. Conversely, brand claims $P M P Q$ decreased by $21.0 \%$, from 1.76 in 2007 Q1 to 1.39 in 2009 Q4. As a result, mean GDR per plan increased by 9.8 percentage points or a relative change of $18.2 \%$, from $53.9 \%$ in 2007 Q1 to $63.7 \%$ in 2009 Q4. Over the 3 years, average gross pharmacy costs PMPQ increased by $14.0 \%$ from $\$ 242$ to $\$ 276$. The relationship between GDR and gross pharmacy expenditures, estimated in the linear fixed effects multivariate models, varied depending upon whether or not total utilization was controlled. In the first model, which did not control for total utilization, each percentage point increase in GDR was associated with a $2.5 \%$ reduction in gross pharmacy expenditure. Holding total utilization constant, the reduction in gross pharmacy expenditure for each percentage point increase in GDR was $1.3 \%$.

CONCLUSION: Prescription drug cost savings are realized with increases in GDR. During 2007-2009, each 1 percentage point increase in GDR was associated with a drop of $2.5 \%$ in gross pharmacy expenditures. Slightly more than one-half of the savings was derived from the lower drug prices enjoyed with brand-to-generic conversions. The remaining savings, however, were attributed to reduced brand drug utilization. Pharmacy benefit managers and plan sponsors should exercise care to ensure that increases in GDR do not represent reductions in appropriate medication use.

J Manag Care Pharm. 2010;16(7):502-06

Copyright $\odot 2010$, Academy of Managed Care Pharmacy. All rights reserved.

\section{What is already known about this subject}

- In 2009, generic medications saved the U.S. health care system nearly $\$ 140$ billion, and more than $\$ 824$ billion in savings has accrued to Americans over the past 10 years. Encouraging generic drug use is a primary objective of pharmacy benefit design, which influences patients' access to and cost of prescription drugs.

- The generic dispensing ratio (GDR), the proportion of all prescriptions dispensed as generic, is the most common measure of generic drug use. Since increases in GDR contribute to decreases in pharmacy benefit costs, benefit design alterations are often considered in light of their anticipated impact on GDR. Benefit design modeling typically assumes constant utilization in the baseline and projected ("what if") period.

- Current estimates from nonpeer-reviewed analyses suggest that a 1 percentage point increase in GDR can reduce annual gross pharmacy expenditures by $1 \%-2 \%$.

\section{What this study adds}

- Using plan sponsor data from 2007-2009 for approximately 14 million beneficiaries, a 1 percentage point increase in GDR was associated with a $2.5 \%$ reduction in gross pharmacy costs. Holding total utilization constant, the reduction in gross pharmacy costs associated with a 1 percentage point GDR increase was $1.3 \%$

- This study confirms that, in practice, prescription drug cost savings from GDR increases derive both from brand-to-generic conversions and from reductions in brand utilization.

$\mathrm{O}$ $\mathrm{f}$ the $\$ 2.3$ trillion spent on health care in the United States in 2008, more than $10 \%$ ( $\$ 234.1$ billion) was for prescription drugs. ${ }^{1}$ Yet, since 2003 annual increases in prescription drug expenditures have slowed considerably. This deceleration is attributed in large part to growth in the availability and use of generic drugs. ${ }^{2,3}$ A recent report estimated that generics saved the U.S. health care system $\$ 824$ billion from 2000 to 2009, including $\$ 139.6$ billion in $2009 .{ }^{4}$ These savings resulted from substantially lower drug prices. For instance in 2008, the average per prescription brand and generic drug prices in community pharmacies were $\$ 137.90$ and $\$ 35.22$, respectively. ${ }^{5}$

Given the savings potential and robust pipeline, generic pharmaceuticals have become increasingly important for plan sponsors. Many elements of a pharmacy benefit, such as copayments, step therapy, and dispense-as-written penalties, are designed to encourage the utilization of generics over brands. To measure success in this regard, pharmacy benefit management companies (PBMs) and their clients often turn 
to the generic dispensing ratio (GDR), the proportion of all prescriptions dispensed as a generic. GDR has become a key performance metric for the Centers for Medicare \& Medicaid Services, as well as for managed care. ${ }^{2,6}$ Moreover, innovations in plan design and educational interventions are often considered because of their anticipated impact on GDR.

Despite the widespread adoption of GDR as an indicator of pharmacy benefit performance, no peer-reviewed published report has analyzed the financial savings that payers realize with increases in GDR. In annual pharmacy trend reports, PBMs generally report that a $1 \%$ increase in GDR yields a savings of $1 \%$ to $2 \%$ in total pharmacy expenditures. ${ }^{7,8}$ One might conclude that because the relationship between GDR and gross pharmacy cost is defined by a mathematical equation, it is therefore easily calculable and does not warrant peerreviewed publication. Indeed, given a starting GDR value and known relative prices for brands and generics, one can derive the percentage change in drug expenditures resulting from an absolute change in GDR. This calculation is accurate, however, only under an assumption that total utilization remains constant-that is, assuming GDR changes result exclusively from brand-to-generic conversion. Of course, GDR can also increase because of lower brand use without a compensating increase in generic use (i.e., decreasing denominator). Therefore, the actual savings realized from increases in GDR are not readily derived without information on the absolute levels of brand and generic utilization.

In this study, we estimated the relationship between GDR and gross pharmacy expenditures and the extent to which savings from increases in GDR were due to brand-to-generic conversion versus net reductions in brand use.

\section{Methods}

\section{Study Sample and Variable Construction}

An analytical dataset was constructed using paid pharmacy claims from 548 self-insured employers covering nearly 14 million members from January 1, 2007, through December 31, 2009. All included plan sponsors insured a minimum of 500 members and had both retail and mail-service pharmacy benefits managed by CVS Caremark throughout the entire 3-year study period. The claims data for each plan were aggregated into calendar quarters, resulting in a total of 6,576 observations (i.e., $548 \times 12$ ). Measures of plan membership demographics were generated, including percent male, proportion in each of 5 age groups in years $(0-11,12-18,19-39,40-64$, and 65 or older), and the concentration of individuals residing in each of 5 geographic regions (West, Midwest, Northeast, South, and other/unknown).

Several drug utilization variables were constructed: generic utilization rate-the number of generic prescriptions filled per eligible plan member per quarter (PMPQ); brand utilization rate-the number of brand prescriptions filled PMPQ; singlesource brand (SSB) utilization rate-the number of prescriptions filled PMPQ for brands without a chemically equivalent generic available; and multisource brand (MSB) utilization rate-the number of prescriptions filled PMPQ for brands with a chemically equivalent generic available. In addition to these absolute measures of utilization, 2 relative measures of generic drug use were created for each plan and quarter. The generic substitution ratio (GSR) was calculated as the number of generic drug claims divided by the sum of generic and MSB drug claims. The GDR was derived as the proportion of all claims filled as generic. For all pharmacy utilization metrics, claims were adjusted to 30-day equivalent prescriptions to account for the extended days supply associated with mailservice pharmacy use.

PMPQ measures of expenditures paid in total (gross), by members, and by plans (net of member cost share) were calculated from paid amounts listed on adjudicated pharmacy claims. As the key dependent variable employed in the models discussed below, gross pharmacy expenditure PMPQ was logtransformed in order to approximately normalize its skewed distribution and to allow for the presentation of GDR effects in terms of percentage changes in gross prescription drug costs.

\section{Econometric Analysis}

Linear fixed effects models were estimated to examine the association of GDR with gross pharmacy costs. This econometric technique makes use of within-subject variation only to identify the effects of included regressors. Consequently, the effects of all observed and unobserved characteristics that do not vary over time, including potential confounders, are removed from the analysis. ${ }^{9}$ Stated differently, the analysis examined plan-specific quarterly changes in gross pharmacy costs as related to quarterly changes in GDR. Two models were specified. In both, the dependent variable was log-transformed gross pharmacy costs PMPQ, and the independent variables were GDR, demographic characteristics (described previously), and a vector of quarterly time dummy variables that controlled for time-varying characteristics common to all clients (e.g., pharmaceutical pipeline, price inflation). The 2 models differed in that one included an additional independent variable, total drug utilization (i.e., total number of 30-day adjusted prescriptions PMPQ). Results of the 2 models were compared in order to decompose pharmacy cost savings from GDR increases into those from brand-to-generic conversions versus those from decreases in brand utilization. All analyses were conducted using Stata/MP 11.1 (StataCorp, College Station TX) and in accordance with privacy standards.

\section{Results}

Table 1 presents demographic characteristics, pharmacy utilization, and costs for each quarter for the sample of 548 employers over the 3-year study period (2007-2009). The demographic profile of the plan sponsors' membership was relatively stable over time with a closely balanced gender distribution (49.2\%49.5\% male) and approximately two-thirds of participants aged 19 to 64 years. About two-thirds of plan members resided in either the Midwest or the South. Together, the 548 plan sponsors covered nearly 14 million individuals by the end of 2009 . 
The number of generic claims PMPQ increased by $18.4 \%$ during the study period, from 2.01 in 2007 Q1 to 2.38 in 2009 Q4. Conversely, brand utilization rates decreased by $21.0 \%$, from 1.76 claims PMPQ in 2007 Q1 to 1.39 claims PMPQ in 2009 Q4. As a result, mean per plan GDR increased by 9.8 percentage points or a relative change of $18.2 \%$, from $53.9 \%$ in 2007 Q1 to $63.7 \%$ in 2009 Q4. MSB utilization remained stable, varying between 0.07 and 0.06 claims PMPQ, while SSB utilization declined steadily from 1.69 claims PMPQ in 2007 Q1 to 1.33 claims PMPQ in 2009 Q4. Throughout the study period, mean per plan GSR increased from $96.7 \%$ to $97.6 \%$. Over the 3 years, gross pharmacy costs PMPQ increased by $14.0 \%$ from $\$ 242$ to $\$ 276$. The mean per plan member costsharing percentage declined from $21.9 \%$ in 2007 Q1 to $18.5 \%$ in 2009 Q4.

Table 2 presents coefficient estimates from the 2 models of log-transformed gross pharmacy costs. In Model 1 , a 1 percentage point increase in GDR was significantly $(P<0.001)$ associated with a reduction of $2.5 \%$ in gross pharmacy costs, controlling for demographics and time trends. When total utilization PMPQ was added and held constant in Model 2, the reduction in pharmacy costs associated with a 1 percentage point increase in GDR was 1.3\% $(P<0.001)$.

\section{Discussion}

Increases in GDR are associated with reductions in overall pharmacy expenditures for 2 reasons: brand-to-generic conversion and reduced brand use (not otherwise substituted with a generic). Under the former scenario, the number of generic prescriptions increases (i.e., the GDR numerator is increasing) with an equal decrease in the number of brand prescriptions (i.e., the GDR denominator is unchanged). Total drug costs decline in this scenario because prices are lower for generic drugs than for their branded counterparts. GDR can also increase, however, when the number of brand prescriptions is reduced without an equal change in generic prescriptions (i.e., the GDR denominator is decreasing). Pharmacy costs decline in this scenario because fewer total prescriptions are filled.

The present study was an empirical analysis of the relationship between GDR and gross pharmacy costs. Specifically, changes in these metrics were examined over time to quantify GDR's association with drug expenditures and to decompose this relationship into its 2 components. Among the sample of 548 employers from 2007 through 2009, a 1 percentage point increase in GDR was associated with a reduction of $2.5 \%$ in gross pharmacy expenditures. After adjusting for total utilization, an approach that isolated the brand-to-generic conversion portion of the effect, a 1 percentage point increase in GDR was associated with a reduction of $1.3 \%$ in gross pharmacy expenditures. This finding suggests that roughly one-half $(1.3 \%$ of $2.5 \%$ ) of the savings realized in practice from increasing GDR is due to the price discounts enjoyed with brand-to-generic conversions. The other half of pharmacy cost savings from rising GDR can be attributed to reductions in brand use not otherwise replaced by generic utilization.
In recent years, generic drug use has surged largely due to the confluence of both supply- and demand-side factors. Increased availability of generics following brand drug patent expirations, legislation that allows (or, in some states, requires) pharmacies to automatically substitute a generic for a brand, and some community pharmacy networks that have financial incentives such as higher dispensing fees for generic drugs and/or more generous maximum allowable cost (MAC) prices for generic drugs have been the dominant supply-side drivers that have contributed to increased generic utilization. On the demand side, PBMs and pharmacy plan sponsors have adopted increasingly aggressive benefit designs and interventions to encourage generic drug use, examples of which include multiple formulary tiers, higher member cost shares for brands, deductibles, step therapy, and prior authorization. ${ }^{10}$ As a result of these market conditions, generic drugs are dispensed nearly $98 \%$ of the time when both a brand and generic drug with the same active ingredient(s) are available.

With GSR at 98\%, SSBs represent more than 95\% of all brand drug prescriptions dispensed. Consequently, incremental improvements in generic use are predominantly the result of either an SSB becoming generically available or a patient or physician actively choosing a generic drug over a therapeutically interchangeable brand with a different active ingredient. The economic incentives embedded in pharmacy benefit designs have proven successful in dissuading MSB use, but results are mixed for SSB-to-generic conversions. Indeed, pharmacy benefit designs that impose barriers to access or differentially increase brand drug out-of-pocket costs do so with some risk of reducing appropriate use. ${ }^{11}$ The present study highlights the fact that GDR, the preferred relative measure of generic drug utilization, if examined apart from its absolute utilization components, masks the extent to which this reduction may be occurring.

The fixed-effects modeling approach allows for a more accurate evaluation of changes in GDR and pharmacy costs over time, with adequate accounting for population shifts in demographics, utilization, and secular changes (in our case, with the inclusion of variables for calendar quarter). This econometric technique uncovers an association not otherwise suggested by the simple descriptive results presented in Table 1.

\section{Limitations}

Despite the general strengths of the fixed-effects modeling approach, the present study is limited in at least 2 ways. First, the estimated impact of GDR on gross pharmacy costs (with and without control for overall drug utilization) may be biased despite the use of fixed effects modeling, which controls for time-invariant confounders. Since total cost is the product of utilization and price, brand and generic drug prices are likely correlated with both GDR (via price elasticity of demand) and total pharmacy costs. Thus, to the extent that drug prices changed over time during the study period (beyond the secular price trends common to all clients, controlled for by the quarterly time indicators) the impact of GDR on gross pharmacy 
Prescription Drug Costs and the Generic Dispensing Ratio

\section{TABLE 1 Demographic Characteristics, Pharmacy Utilization, and Costs Among Employer Plan Sponsors ( $N=548$ )}

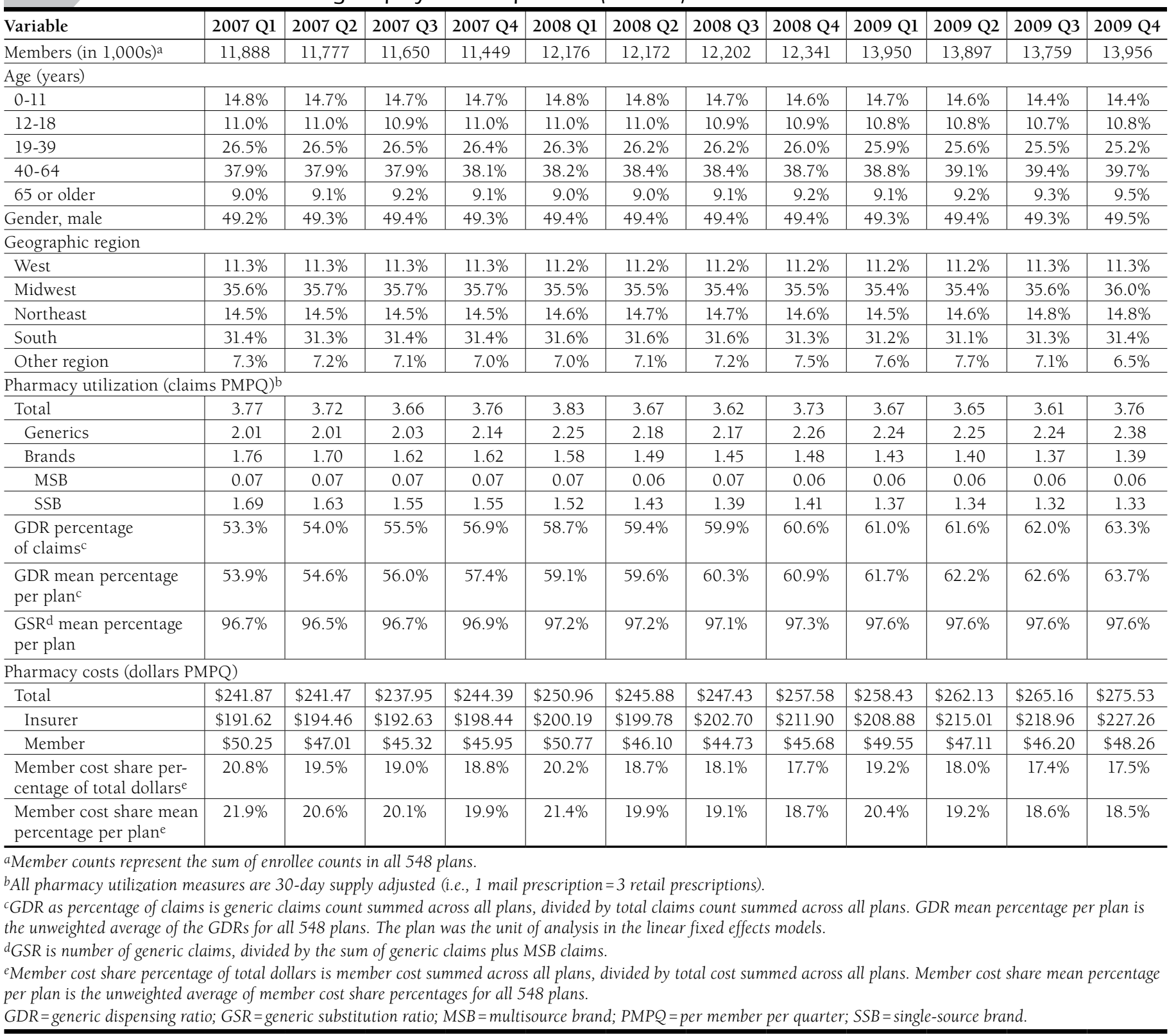

costs may be over- or understated in the present analysis. Additionally, other time-varying confounders, such as changes to formularies and introduction of step-therapy or prior authorization programs, were not measured in this study and could have affected study results. Second, while we speculate that reductions in total utilization may represent reductions in appropriate medication use, other explanations are plausible. For instance, patients facing a step-therapy or dispenseas-written penalty may have obtained samples from their physicians, selected an over-the-counter medication instead, or paid for the desired prescription in full without using their prescription drug insurance benefit. ${ }^{12}$

\section{Conclusion}

Prescription drug cost savings are realized with increases in GDR. During a 3-year study period from 2007 through 2009, each 1 percentage point increase in GDR was associated with a reduction of $2.5 \%$ in gross pharmacy expenditures. Slightly 


\begin{tabular}{|c|c|c|}
\hline & $\begin{array}{c}\text { Model } 1 \\
\text { Coefficient Estimates } \\
\text { (Standard Errors) }\end{array}$ & $\begin{array}{c}\text { Model } 2 \\
\text { Coefficient Estimates } \\
\text { (Standard Errors) }\end{array}$ \\
\hline \multirow{2}{*}{ GDR } & $-2.4825^{b}$ & $-1.3376^{b}$ \\
\hline & $(0.3073)$ & $(0.2099)$ \\
\hline \multirow{2}{*}{$\begin{array}{l}\text { Total pharmacy } \\
\text { utilization PMPQ }\end{array}$} & \multirow{2}{*}{ - } & $0.1803^{b}$ \\
\hline & & $(0.0090)$ \\
\hline \multirow{2}{*}{ Age, 0 to 11 years } & $-1.2184 \mathrm{c}$ & $-0.5598^{d}$ \\
\hline & $(0.4776)$ & $(0.3312)$ \\
\hline \multirow{2}{*}{ Age, 12 to 18 years } & -0.5222 & -0.2721 \\
\hline & $(0.4612)$ & $(0.3542)$ \\
\hline \multirow{2}{*}{ Age, 40 to 64 years } & $0.6623^{b}$ & 0.1734 \\
\hline & $(0.2372)$ & $(0.1528)$ \\
\hline \multirow{2}{*}{ Age, 65 years or older } & $1.0496^{\mathrm{b}}$ & -0.1728 \\
\hline & $(0.2662)$ & $(0.1766)$ \\
\hline \multirow{2}{*}{ Gender, male } & $-0.8203^{c}$ & -0.2560 \\
\hline & $(0.3680)$ & $(0.2630)$ \\
\hline \multirow{2}{*}{$\begin{array}{l}\text { Geographic region, } \\
\text { West }\end{array}$} & -0.0213 & 0.0908 \\
\hline & $(0.2015)$ & $(0.1346)$ \\
\hline \multirow{2}{*}{$\begin{array}{l}\text { Geographic region, } \\
\text { Northeast }\end{array}$} & 0.2888 & $0.3081^{c}$ \\
\hline & $(0.1883)$ & $(0.1284)$ \\
\hline \multirow{2}{*}{$\begin{array}{l}\text { Geographic region, } \\
\text { South }\end{array}$} & $0.2611^{c}$ & $0.2243^{c}$ \\
\hline & $(0.1323)$ & $(0.0980)$ \\
\hline \multirow{2}{*}{$\begin{array}{l}\text { Geographic region, } \\
\text { other }\end{array}$} & $0.2364^{\mathrm{d}}$ & $0.2329^{c}$ \\
\hline & $(0.1387)$ & $(0.0996)$ \\
\hline $\mathrm{R}^{2}$ & 0.5540 & 0.7732 \\
\hline
\end{tabular}

${ }^{A} A$ vector of 11 quarterly time dummy variables was included in both models but suppressed in the table. Excluded categories were: 19 to 39 years, female, Midwest, and 2007 Q1. Robust standard errors reported in parentheses.

${ }^{b} P<0.01$.

${ }^{c} P<0.05$.

$d P<0.10$.

$G D R=$ generic dispensing ratio; $P M P Q=$ per member per quarter .

more than one-half of the savings was derived from the lower drug prices enjoyed with brand-to-generic conversions. The remaining savings, however, can be attributed to reduced brand drug utilization. The critical challenge in designing pharmacy benefits is to find the optimal balance between access to appropriate medications and cost management. ${ }^{13}$ Pharmacy benefit managers and plan sponsors should exercise care to ensure that increases in GDR are not from discontinuation of or reduced adherence to appropriate therapy.

\section{DISCLOSURES}

Both authors are employed by and hold stock options in CVS Caremark, a pharmacy benefits management company. The research was funded entirely by CVS Caremark.

Liberman and Roebuck shared equal responsibility for concept and design, data interpretation, and revision of the manuscript. Data collection was performed by Roebuck, and writing of the manuscript was performed primarily by Liberman with the assistance of Roebuck.

\section{Authors}

JOSHUA N. LIBERMAN, PhD, is Vice President, Strategic Research, and M. CHRISTOPHER ROEBUCK, MBA, is Director, Health Economics, CVS Caremark, Hunt Valley, Maryland.

AUTHOR CORRESPONDENCE: Joshua N. Liberman, PhD, CVS Caremark, 11311 McCormick Rd., Ste. 230, Hunt Valley, MD 21031. Tel.: 410.785.2130; E-mail: josh.liberman@caremark.com.

\section{REFERENCES}

1. Hartman M, Martin A, Nuccio O, Catlin A, National Health Expenditure Accounts Team. Health spending growth at a historic low in 2008. Health Aff (Millwood). 2010;29(1):147-55.

2. Theodorou AA, Slezak J. Factors affecting pharmacy trends in 2008. Am J Pharm Ben. Spring 2009;1(1):53-59. Available at: http://ajpblive.com/media/ pdf/AJPB_09Spring_Theodoru53to59.pdf. Accessed August 11, 2010.

3. Generic Pharmaceutical Association. 2009 annual report. Available at: http://www.gphaonline.org/media/media-kit. Accessed August 11, 2010.

4. Generic Pharmaceutical Association. Generic medicines saved U.S. health care system $\$ 139.6$ billion in 2009; $\$ 824$ billion saved over the last decade. July 26, 2010. Available at: http://www.gphaonline.org/media/press-releases/2010/generic-medicines-saved-us-health-care-system-1396-billion-2009824-billio. Accessed August 11, 2010.

5. National Association of Chain Drug Stores. Industry facts-at-aglance. Undated webpage. Available at: http://nacds.org/wmspage. cfm?parml=6536\#rx. Accessed August 11, 2010.

6. Center for Medicare \& Medicaid Services. Center for Beneficiary Services. Part D sponsors generic dispensing rate (GDR) performance metrics.

Memorandum. November 9, 2006. Available at: http://www.cms.hhs.gov/ PrescriptionDrugCovContra/downloads/MemoGDRPerfMetric_11.09.06.pdf Accessed August 11, 2009.

7. Prime Therapeutics. Connect and create value: 2009 drug trend insights. Available at: http://www.primetherapeutics.com/ PDF/2009PrimeDrugTrends.pdf. Accessed August 11, 2010.

8. CVS Caremark. 2009 trends Rx report: driving best-in-class results with proactive pharmacy care. Available at: http://info.cvscaremark.com/sites/cvscaremark.com/files/TrendsRx_2009.pdf. Accessed August 11, 2010.

9. Wooldridge JM. Econometric Analysis of Cross Section and Panel Data. Cambridge, MA: MIT Press; 2002.

10. The Kaiser Family Foundation and the Health Research and Educational Trust. Employer health benefits: 2009 annual survey. Section 9. Prescription drug benefits. Available at: http://ehbs.kff.org/pdf/2009/7936.pdf. Accessed August 11, 2009.

11. Goldman DP, Joyce GF, Zheng Y. Prescription drug cost sharing: associations with medication and medical utilization and spending and health. JAMA. 2007;298(1):61-69. Available at: http://jama.ama-assn.org/cgi/content/full/298/1/61. Accessed August 11, 2010.

12. Cox ER, Henderson R, Motheral BR. Health plan member experience with point-of-service prescription step therapy. J Manag Care Pharm. 2004;10(4):291-98. Available at: http://www.amcp.org/data/jmcp/ Research-291-298.pdf.

13. Shrank WH, Porter ME, Jain SH, Choudhry NK. A blueprint for pharmacy benefit managers to increase value. Am J Manag Care. 2009;15(2):8793. Available at: http://www.ncbi.nlm.nih.gov/pmc/articles/PMC2737824/ pdf/nihms110319.pdf. Accessed August 11, 2010. 